Cerebrovasc Dis 2005;20:415-416

DOI: $10.1159 / 000088666$

\section{Angiographic Findings of Moyamoya Vessels in a Patient with Rheumatoid Arthritis}

Maurizio Paciaroni, Sara Micheli, Valeria Caso, Michele Venti, Andrea Alberti, Paolo Milia, Clotilde Balucani, Sergio Biagini, Giancarlo Agnelli

Stroke Unit, University of Perugia, Perugia, Italy

Moyamoya vessels (multiple progressive occlusion of intracranial arteries with typical smoke spirals) have rarely been reported in patients older then 50 years. There are few reports on these typical angiographic findings in patients with dysimmune disease, and they have been described essentially in patients with systemic lupus erythematosus and Sjogren's syndrome. We report the case of a 74year-old Caucasian woman, with hypertension as the only risk factor for atherosclerosis, affected by rheumatoid arthritis (RA) who had moyamoya vessels on angiography.

The patient had recurrent transient ischemic attacks during anticoagulant therapy given for previous recurrent deep venous thrombosis. Magnetic resonance imaging demonstrated cortical and subcortical multiple ischemic lesions. Conventional angiography (CA) showed occlusion of the right internal carotid artery (ICA) in the terminal portion and stenosis of the proximal right ICA with occlusion of the proximal portion of the right middle cerebral artery. Moreover, the patient suffered from symmetrical aching and shoulder, knee and hand stiffness responsive to low-dose corticosteroid therapy (prednisone $25 \mathrm{mg}$ per day). ESR was 117, reactive C protein (RCP) $10.5 \mathrm{mg} / \mathrm{dl}$ and rheumatoid factor $650 \mathrm{UI} / 1$. High ESR, RCP and rheumatoid factor values were present before ischemic events and confirmed during follow-up. Search for other inflammatory and immunitary parameters was negative as well as antiphospholipid antibodies. Nineteen months later, after new ischemic events involving the left occipital cortex with persistent right lateral homonymous hemianopia, a second cerebral CA was performed. CA demonstrated occlusion of the left cerebral posterior artery, right ICA terminal portion tight stenosis, left ICA proximal tract irregular profiles and occlusion of the same vessel in the terminal portion with newly developed moyamoya vessels prevalent in the left basal area where they appeared in the shape of smoke spirals (fig. 1). Prednisone was increased (75 mg per day) and anticoagulation was continued. After 6 months of follow-up the patient remained asymptomatic.

This is the first report in the literature of a patient with moyamoya vessels associated with RA.
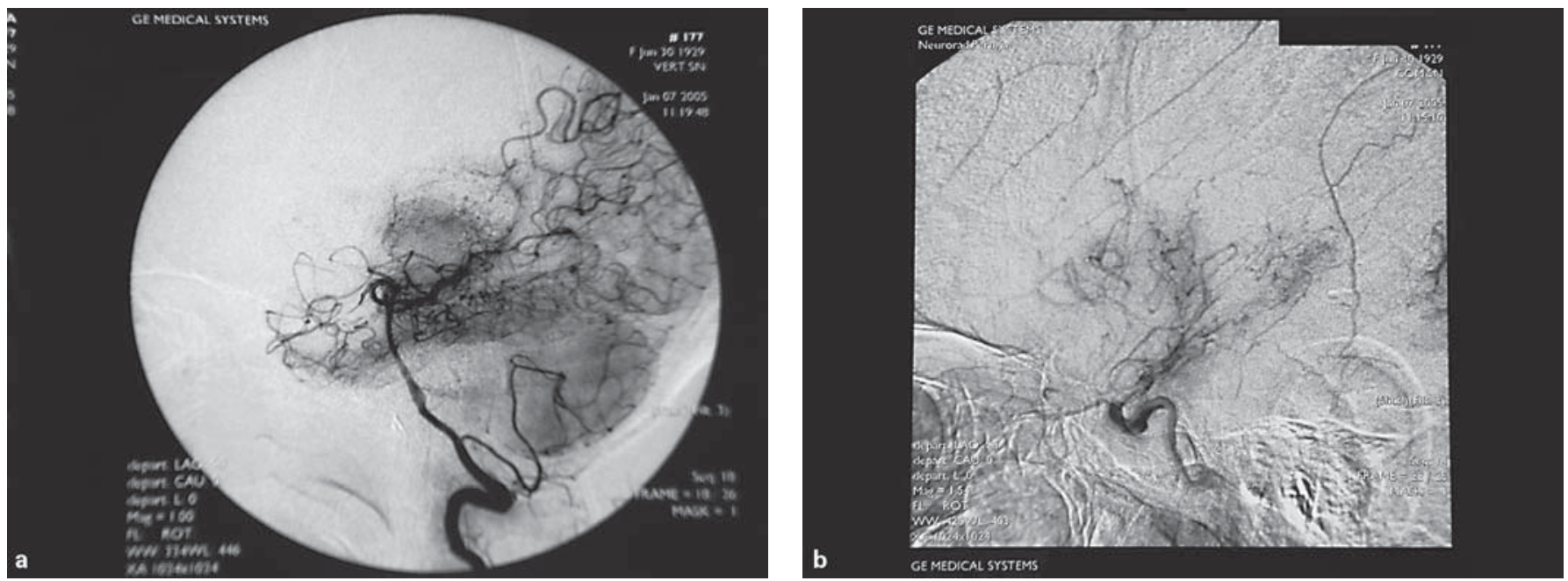

Fig. 1. Multiple progressive occlusion of intracranial arteries with typical smoke spirals involving posterior (a) and anterior (b) circulations.

\begin{tabular}{ll}
\hline KARGER & @ 2005 S. Karger AG, Basel \\
Fax +4161306 1234 & $1015-9770 / 05 / 0205-0415 \$ 22.00 / 0$ \\
$\begin{array}{l}\text { E-Mail karger@karger.ch } \\
\text { www.karger.com }\end{array}$ & $\begin{array}{l}\text { Accessible online at: } \\
\text { www.karger.com/ced }\end{array}$
\end{tabular}


What factors may explain the relation between RA and moyamoya vessels? A number of hypotheses could be made but all should be considered as speculative. It is known that inflammation has an important role in RA, and atherosclerosis also has an important inflammatory component $[1,2]$. T cells play a critical role in RA pathogenesis, and recent data also suggest that $\mathrm{T}$-cell abnormalities may play an important role in atherosclerotic plaque instability [3] In addition, other inflammatory markers known to be related to RA (e.g. cytokines, RCP) are also elevated before and at the time of ischemic events [4].

In conclusion, RA might be associated with angiographic findings of moyamoya vessels, thereby leading to a high risk of cerebrovascular events.

\section{References}

1 Ross R: Atherosclerosis: an inflammatory disease. N Engl J Med 1999;340: 115-126.

2 Drouet L: Atherosclerosis as a systemic disease. Cerebrovasc Dis 2002; 13(suppl 1):1-6.

3 Liuzzo G, Goronzy JJ, Yang H, et al: Monoclonal T-cell proliferation and instability in acute coronary syndromes. Circulation 2001;101:28832888.

4 Ridker PM, Cushman M, Stampfer MJ, et al: Inflammation, aspirin, and the risk of cardiovascular disease in apparently healthy men. N Engl J Med 1997;336:973-999.

Maurizio Paciaroni, Stroke Unit and Division of Internal and Cardiovascular Medicine, University of Perugia, Silvestrini Hospital Sant'Andrea delle Fratte, IT-06100 Perugia (Italy)

Tel./Fax +39075 5784100, E-Mail mpaciaroni@libero.it

\section{Announcement}

\section{European Stroke Strategies}

2nd Helsingborg Consensus Conference, Helsingborg, Sweden

March 22-24, 2006

Organizers: WHO Europe, International Society of Internal Medicine, International Stroke Society, European Stroke Council.

Aims: European stroke strategies for the next 10 years will be discussed and an updated document finished.

For detail, please see www.umea-congress.se. 